\title{
Diamantfund i Grønland - lovende udsigter
}

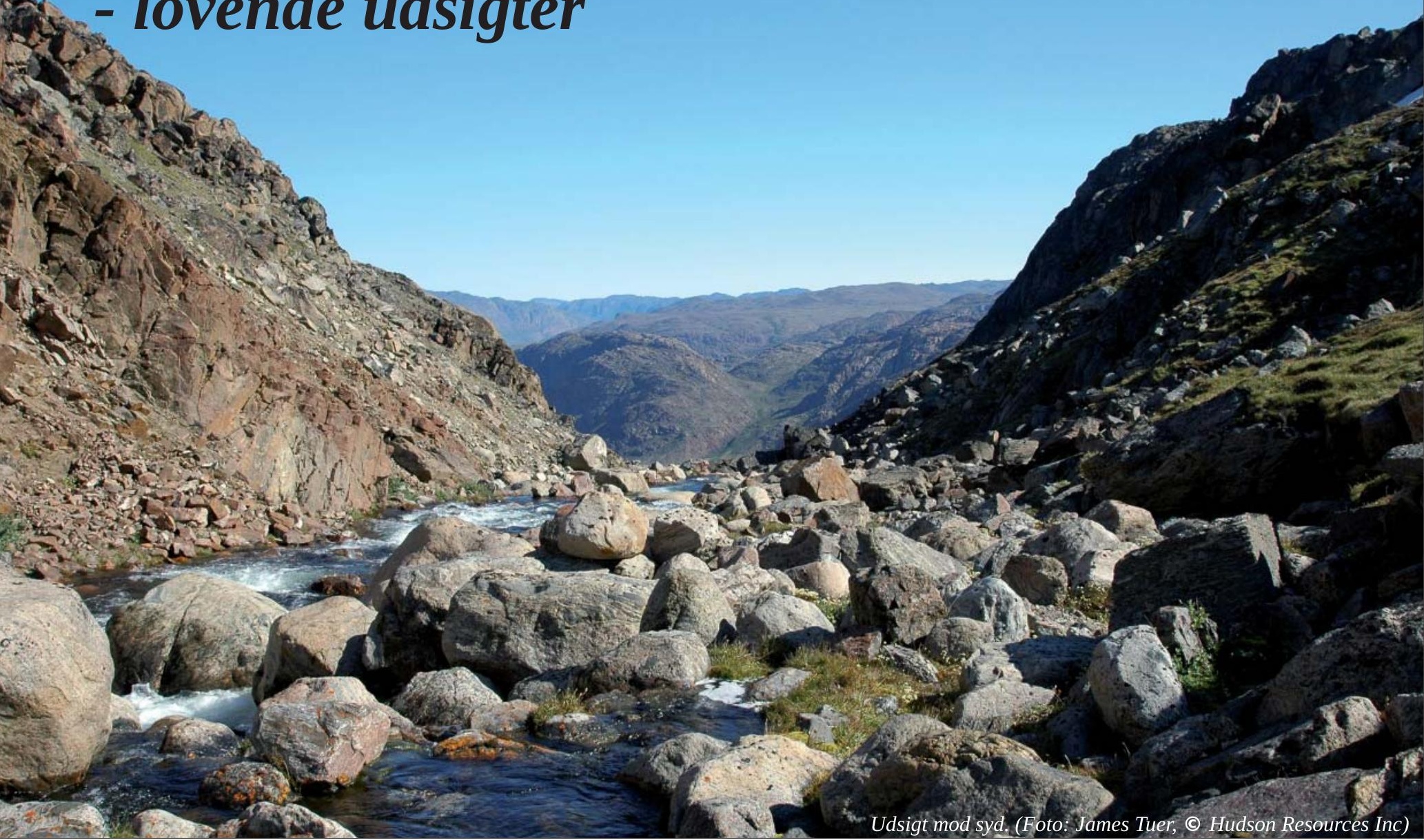

Af geolog Henrik J. Granat, Skov- og Naturstyrelsen

I Vestgrønland er der nu fundet diamanter i mængder og af en størrelse, der giver håb om rentabel minedrift inden for de næste år. Canadiske diamantjægere er begejstrede. Grønlandske politikere er ikke blege for at kæde de ædle sten og selvstændighed sammen.

Diamant er et enestående mineral. Det har en spektakulær geologisk historie, der begyndte for to til tre milliarder år siden 120 $\mathrm{km}$ under jordens overflade.

\section{Grønlands største diamant}

Grønlands hidtil største diamant var blandt de 226 diamanter, canadiske minefolk fandt under deres undersøgelser den forgangne sommer. Diamanten måler helt præcist 2,60 x 2,30 x 2,26 mm, så den kan lige akkurat smutte gennem hullet på en 1-krone. Det lyder umiddelbart ikke af meget, men fordi de 226 diamanter var koncentreret i én prøve på kun godt $150 \mathrm{~kg}$, er det et lovende fund. Præsidenten for det canadiske firma Hudson Resources Inc. James Tuer er meget begejstret for fundene. "Vi tror, at dette nye område markant forhøjer sandsynligheden for at finde en økonomisk rentabel diamantforekomst". Desuden er de fundne diamanter af god form og farve. Der er pink diamanter iblandt, og pink diamanter er altid interessante for smykkeindustrien.

Fundene er gjort i Sarfartoq-området på Grønlands vestkyst sydøst for Søndre Strømfjord, hvor Hudson Resources Inc. har licens til eftersøgning i $733 \mathrm{~km}^{2}$ (omtrent som Falster og Møn tilsammen). Prøven med den store diamant er boret op ved Garnet Lake (Granat Sø). Søen har utvivlsomt fået det navn, fordi højtryksmineralet granat kan findes langs søens bredder. Granat er et blandt flere såkaldte indikatormineraler for diamant, og netop søer i kombination med indikatormineraler er nogle af de spor, diamantjægerne bruger for at finde diamant-

Kortet viser, hvor diamanterne er fundet lige syd for Kangerlussuaq også kendt som Søndre Strømfjord. Ncerheden til fjorden er en stor fordel, hvis der på et tidspunkt skal fragtes materiel ind til området og skibes malm ud fra området. (Grafik: UVH). forekomster. At granat og andre indikatormineraler kan lede til diamanterne, hænger sammen med, at de har en fælles geologisk historie.

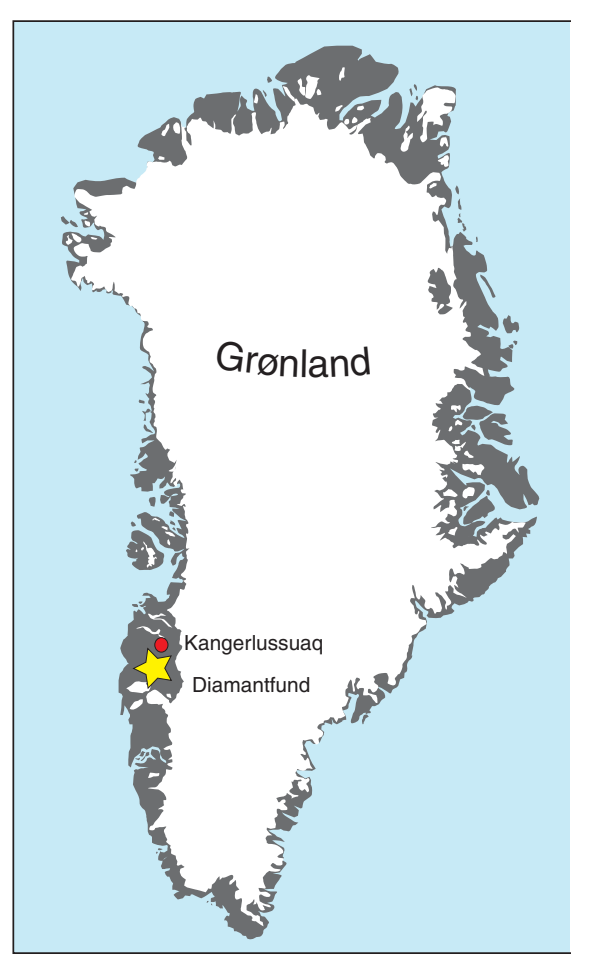



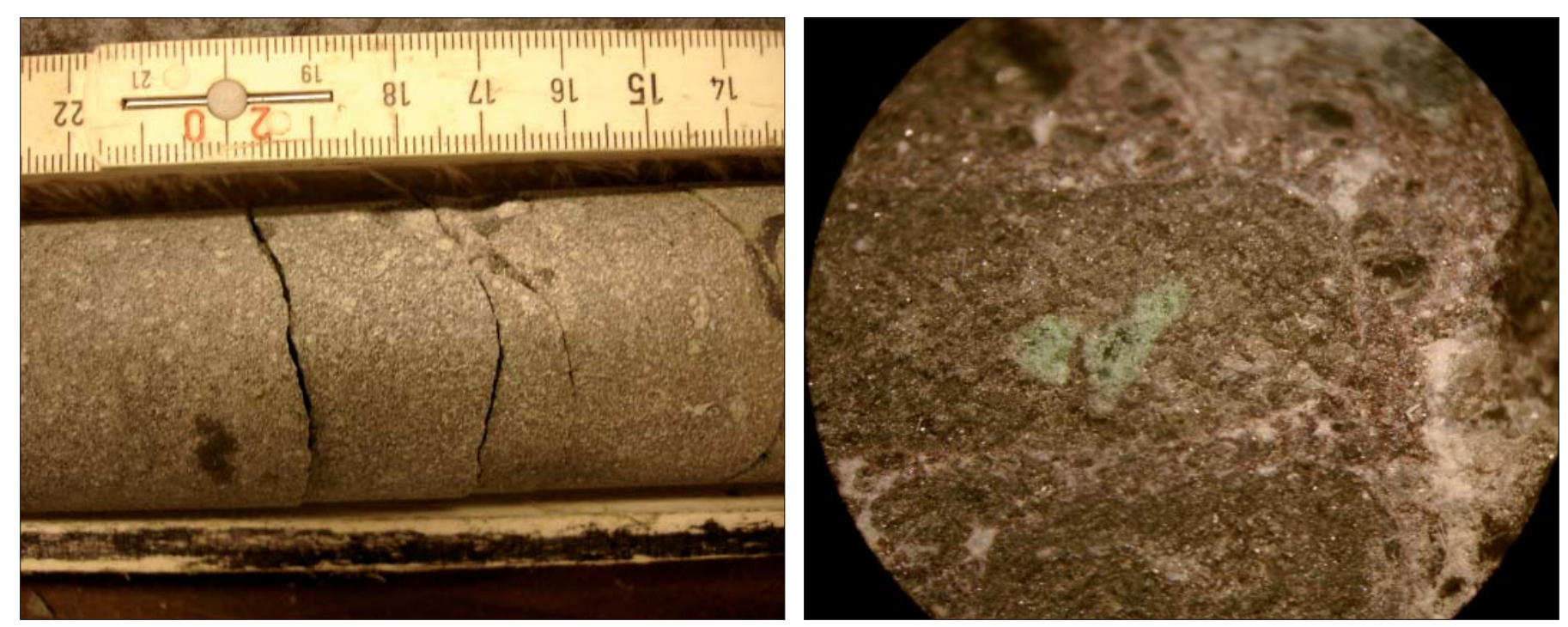

Borekerne af kimberlit. (Foto: Karina Sand, @ Hudson Resources Inc.) Klinopyroksen i kimberlit. (Foto: Karina Sand, @ Hudson Resources Inc.)

\section{Elevatorbjergarten}

Diamanter er to til tre milliarder år gamle. Diamanter er ligesom deres indikatormineraler skabt under stort tryk og høj temperatur tæt over den sejtflydende del af jordens indre, kappen. I ca. $120 \mathrm{~km}$ 's dybde findes såkaldte diamantvinduer, som er betegnelsen for netop den kombination af tryk og temperatur, der skaber grobund for diamant.

Fra mere end 200 km's dybde trængte magma frem mod jordens overflade. Under opstigningen rev den flydende stenmasse stumper af den omgivende bjergart med sig. Passerede magmaet felter med diamant, kom diamanterne med i elevatoren på vej mod overfladen. Da magmaet størknede, stod en blød og porøs vulkansk bjergart tilbage omsluttet af ældre bjergarter.

Bjergarten kaldes kimberlit. Kimberlit findes oftest som to $\mathrm{km}$ lange lodrette gulerodsformede rør eller som skiveformede gange i massiver af hårdere og ældre bjergarter. De gulerodsformede rør er 100 til 500 meter i diameter (se figur nederst til højre på næste side), og de skiveformede gange er sjældent bredere end 5 meter. Fordi kimberlitten er blød, har vejrsmuldring og indlandsis gnavet dybere dér end i den omkringliggende bjergart. Der dannes lavninger, hvori der samles vand, som bliver til søer. De rigeste diamantminer i Canada findes i kimberlitrør under cirkulære søer.

Det var efterretninger om kimberlit og cirkulære søer, der lokkede de første diamantjægere til Grønland. I Grønland er der indtil videre ikke fundet kimberlitrør som i Canada. Det ser ud til, at kimberlitforekomster i Grønland kun findes som skiveformede gange, selvom der er mange cirkulære småsøer. Det betyder, at en eventuel minedrift bliver mere besværlig, da rørene er nemmere at bryde end gangene.

\section{Selvstændighed i undergrunden}

Det er ikke kun diamantfundene, der giver anledning til optimisme. På et nyligt afholdt møde i Fællesrådet for mineralske råstoffer i Grønland, kom det frem, at der i 2005 også er foregået livlig efterforskning efter molybdæn, rubiner og guld samt olie og gas. Rådet har til opgave at afgive indstilling til Landsstyre og Regering om tilladelser til undersøgelser og udvinding.

Grønlandske politikere er ikke blege for at kæde selvstændighed sammen med åbning af nye miner. Landsstyremedlem Jørgen Wæver Johansen udtalte i 2004 til Weekendavisen, at oliefund og nye miner er blandt de faktorer, der bestemmer, hvornår Grønland bliver selvstændigt, og at Grønland bliver selvstændigt, når grønlænderne ikke længere har brug for bloktilskuddet. Det danske bloktilskud til Grønland er mere end tre milliarder kr. årligt.

Måske er det ikke urealistisk for de selvstændighedssøgende grønlændere at sætte deres lid til undergrunden. Grønland første guldmine blev åbnet i 2004. I december 2005 blev der udskibet knap 100.000 tons malm med mineralet olivin til stålindustrien. Dertil komme drømmen om diamanter, olie og gas. I en enkelt diamantmine i Canada udvindes der diamanter for halv milliard kr. pr. år på et sted med en geologi, der ligner den vestgrønlandske. Omvendt kræver etablering af en diamantmine store investeringer. Anlægsomkostningerne kan løbe op i 2 milliarder kr.

Kimberlitrør med 0,00002\% diamant er normalt tilstrækkeligt til at åbne en diamantmine. Kommer minen, går det store 


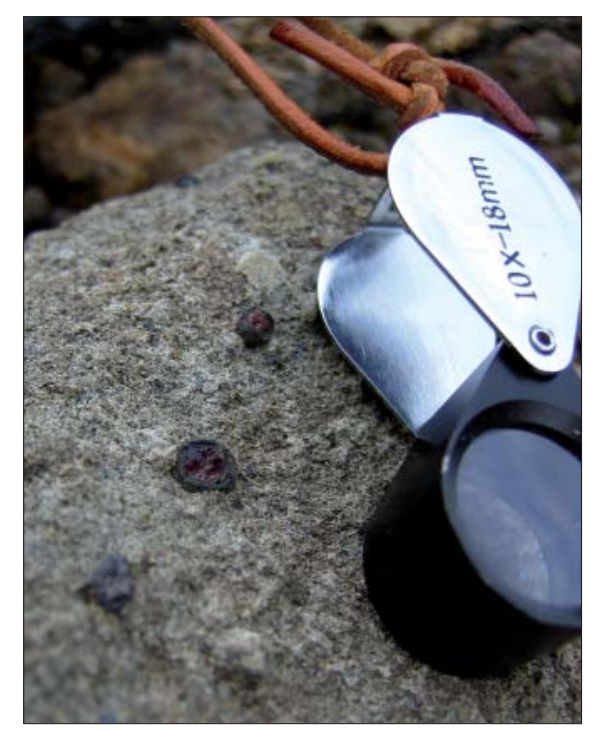

Granat er ét af indikatormineralerne for diamant. (Foto: Mark Hutchison, @ ㅇ Hudson Resources Inc)

knuse- og sigtearbejde i gang. Der skal i gennemsnit knuses 100.000 tons diamantførende kimberlit for at frembringe én sleben diamant på 1 carat. En usleben diamant af smykkekvalitet på 5 carat (1 gram) er mere end $50.000 \mathrm{kr}$. værd.

\section{Næste skridt}

De canadiske diamantjægere kommer tilbage dette forår for at foretage flere undersøgelser. Planerne på kort sigt er at danne sig et mere nøjagtigt billede af kimberlitgangen ved Garnet Lake. Størrelse og form kortlægges gennem seismiske undersøgelser og boringer.

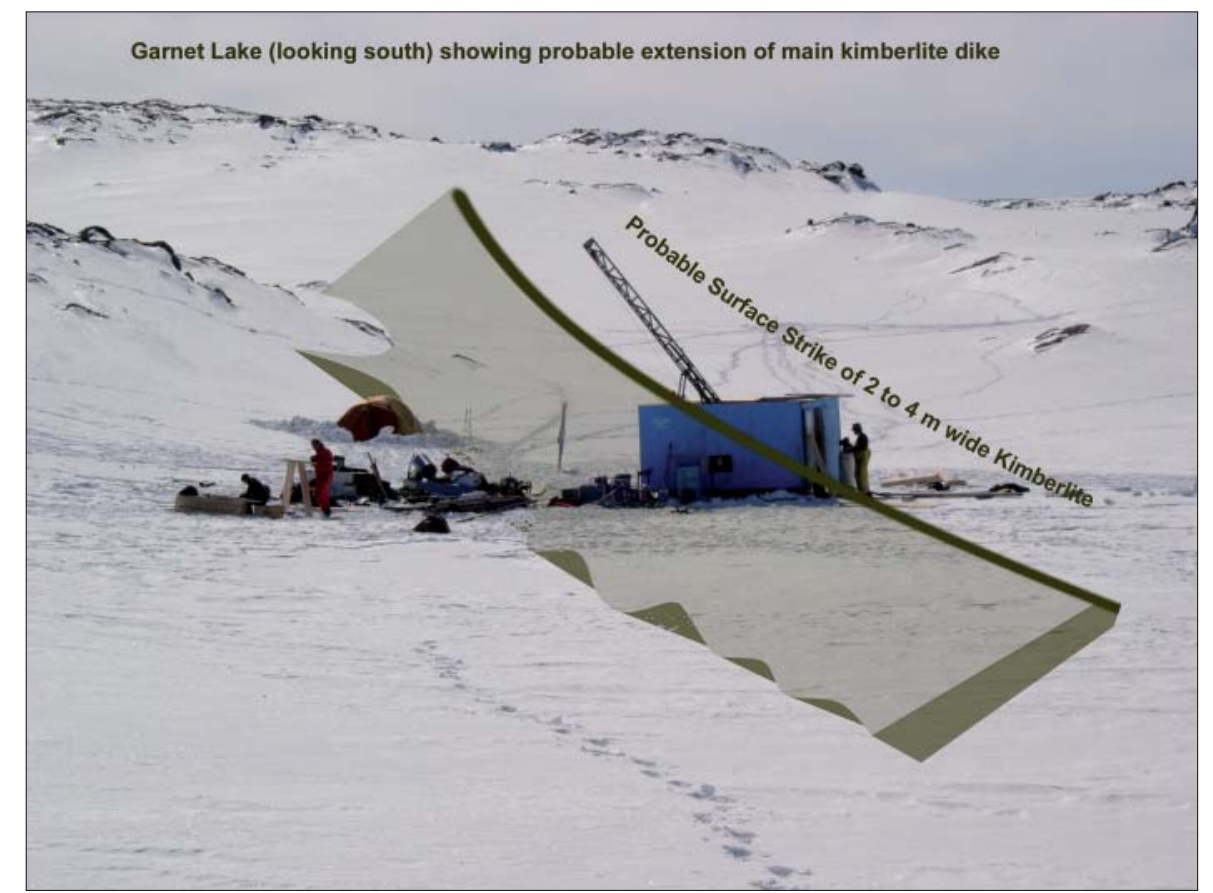

Boreaktivitet på den tilfrosne Garnet Lake. Skyggen på billedet antyder beliggenheden af en to til fire meter bred kimberlitgang. (Foto: @ Hudson Resources Inc)

Desuden skal en 100 tons prøve analyseres for at kunne fastslå diamanternes antal, størrelse og kvalitet. Hudson Resources Inc. forventer, at omkostningerne til undersøgelser i 2006 vil være i omegnen af 11,5 millioner kr.

Figuren nedenfor til højre viser, hvorfor kimberlitrør kaldes "den udslukte vulkans rødder”. Kimberlitrør er de størknede fødegange til vulkaner. De grønlandske kimberlitter er dannet i to omgange: For ca. $600 \mathrm{og}$ for ca. 170 mio. år siden. Vulkankeglen og det omgivende landskab er siden eroderet væk.

Der kendes et sted mellem 5.000 og 6.000 kimberlitrør og nærtbeslægtede lamproitrør i verden.

Kimberlitrør forekommer ofte i klynger, der tilsammen udgør et kimberlitfelt. Der er typisk 40-50 rør inden for et felt fordelt over et $100 \times 100 \mathrm{~km}$ område.

Kimberlitfelterne findes oftest i forbindelse med jordens ældste bjergarter. Det er de arkæiske bjergarter, der er ældre end 2,6 milliarder år.

\section{Faktaboks om diamant}

Diamant har hårdhed 10 og er det hårdeste mineral, man kender. Det består udelukkende af kulstof.

Diamants ekstreme hårdhed skyldes krystalstrukturen. Hvert kulstofatom er bundet til fire andre kulstofatomer med en stærk covalent binding. Herved får alle atomer deres yderste elektronskal fyldt op.

Diamant har sit navn fra det græske adamas, der betyder uovervindelig og af det latinske adamare, der betyder "at forelske sig".

Diamanters størrelse måles i carat: 1 carat $=200 \mathrm{mg}$. I modsætning til karat, der fortæller om gulds renhed: $100 \%$ guld er 24 karat.

Verdens mindste slebne diamant er 0,0006 carat.

Verdens største diamant var på 3.106 carat (ca. 0,6 kg). Den var stor som en mands knytnæve, da den blev fundet ved Pretoria i 1905. Den fik navnet Cullinan-diamanten.

Grønlands hidtil største diamant er 0,0703 carat (ca. $14 \mathrm{mg}$ ), da den blev fundet ved Søndre Strømfjord i 2005.

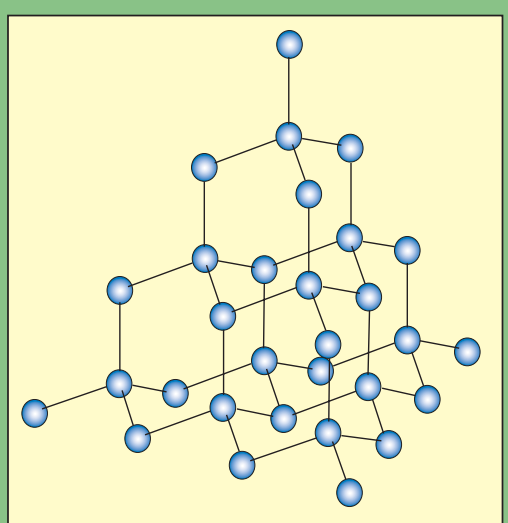

Diamantstrukturen. (Grafik: UVH)

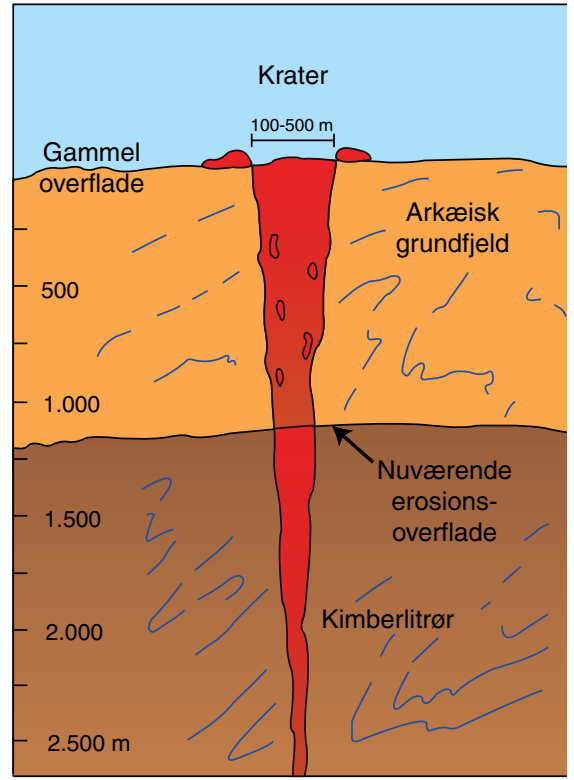

Kimberlitrør, hvorfra diamanterne udvindes. (Grafik: UVH modificeret efter Henriksen, N., 2005: Grønlands geologiske udvikling, Fra fortid til nutid, udgivet af GEUS) 

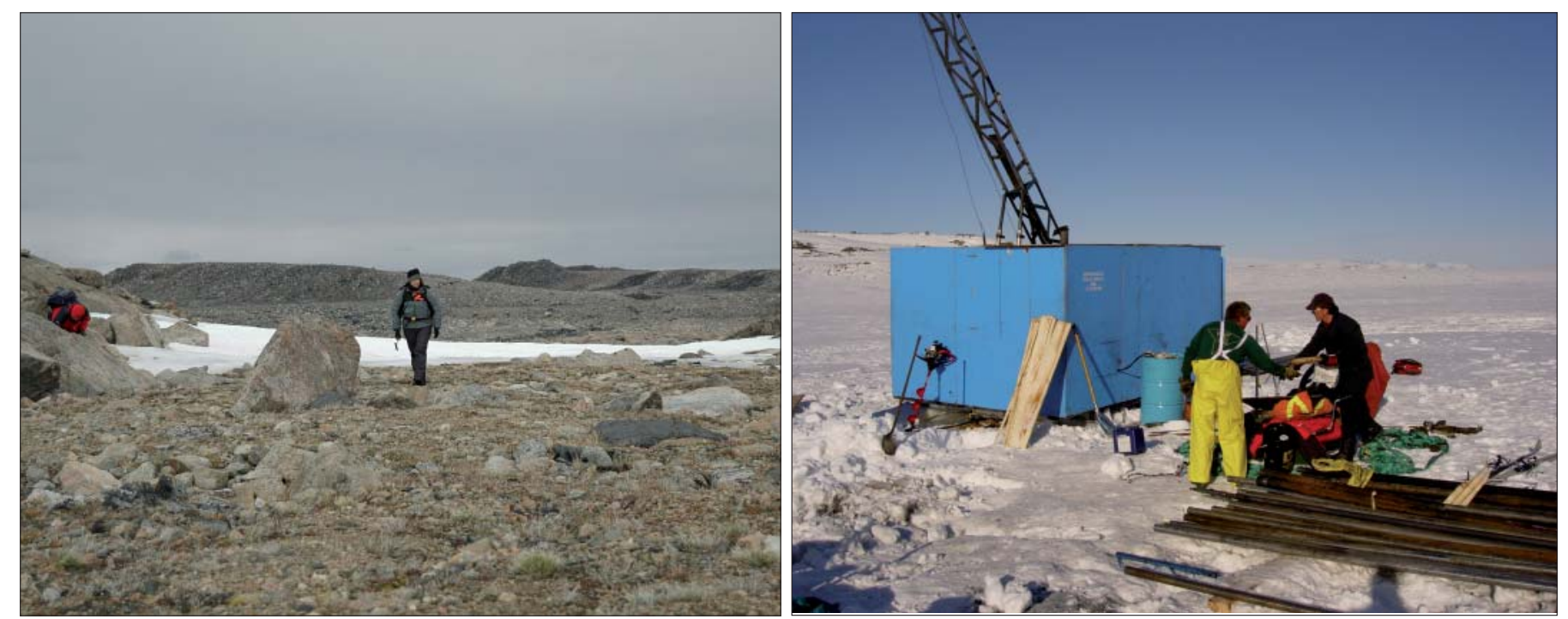

Udsigt over området. (Foto: James Tuer, @ Hudson Resources Inc)

Der arbejdes ved boringen. (Foto: James Tuer, @ Hudson Resources Inc)

Kimberlit er opkaldt efter den Sydafrikanske by Kimberley, der er berømt for sin store diamantmine.

\section{De vigtigste kilder:}

Schønwandt, H.K. 1996: Diamantfund i Grønland, Specialartikel fra GEUS’ Årsberetning for 1996. s. 67-73.

http://www.geus.dk/publications/aarsberetning96/aab96s66-73.htm

Secher, K. \& Jensen, S.M. 2004: Diamond exploration in Greenland.Geology and Ore, Exploration and Mining in Greenland, No. 4 - December 2004. 12 s. http://www.geus. dk/minex/go04001.jpg

Stockmann, G. 2003: Diamantefterforskning i Grønland: Mens vi venter på det store gennembrud. Polarfronten 1/03. http://www. dpc.dk/polarfrontendpc/1_03/Diamanter

Henriksen, N. 2005: Grønlands geologiske udvikling, Fra fortid til nutid. Danmarks og Grønlands Geologiske Undersøgelse. 270 s.

www.hudsonresources.ca (også med tak for at få lov til at anvende fotos).

\section{Følg den videre udvikling på:}

Greenland mineral exploration newsletter: http://www.geus.dk/minex/ minex-uk.htm

Hudson Resources hjemmeside, januar 2006: www.hudsonresources.ca Råstofdirektoratet i Grønland: http:// www.nanoq.gl/Groenlands_Landsstyre/Raastofdirektoratet.aspx

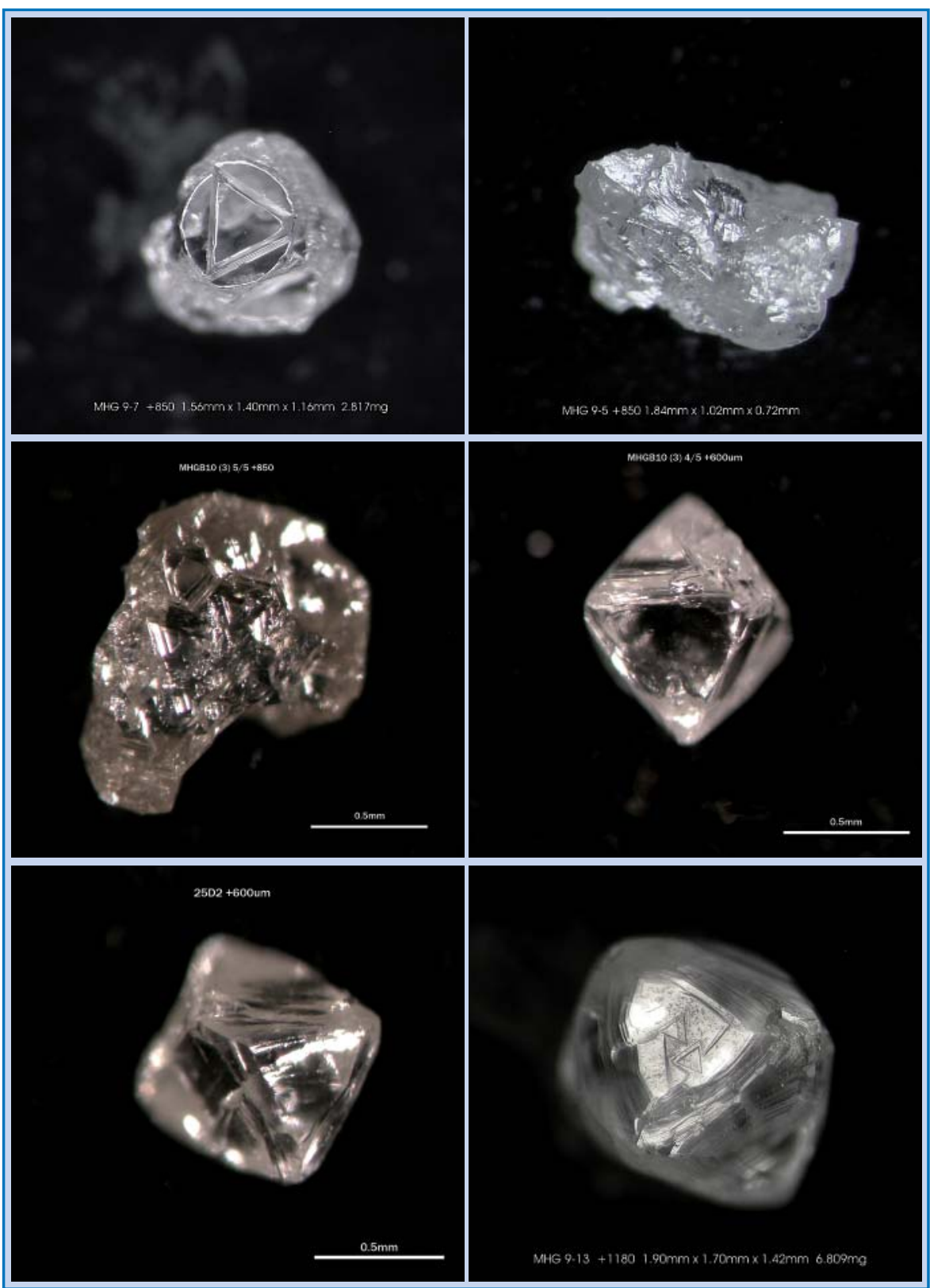

"Hvor der er små fisk, er der store fisk" siger ordsproget. Om det også gcelder de grønlandske diamanter, vil fremtiden vise. På billedet ses diamanter fra Sarfatoq-området. Målepindene er 0,5 mm. (Fotos: @ Saskatchewan Research Council) 